\section{Pesquisar História da África A Partir do Brasil: Mulheres de Moçambique na Revista Tempo (1975-1985)}

\section{Resumo}

Em Moçambique, após a independência, a emancipação da mulher foi assumida como uma das políticas sociais do Estado. Essa política incentivou as mulheres a ocuparem novos papéis sociais e proporcionou-lhes maior visibilidade pública, sendo o seu desenvolvimento noticiado, de modo particular, na revista Tempo. Este artigo aborda, a partir das notícias desse periódico, contradições daquela política direcionada às mulheres e algumas intervenções manifestadas por elas a tal proposta.

Palavras-Chave: Mulheres. Emancipação. Moçambique.

\section{Abstract}

In Mozambique, after independence, the emancipation of women was assumed as one of the state's social policies. This policy encouraged women to take on new social roles and provided them with greater public visibility, with their development being reported, in particular, in the magazine Tempo. This article addresses, from the news of this periodical, contradictions of that policy directed at women and some interventions manifested by them to such proposal.

Keywords: Women. Emancipation. Mozambique.

\section{Introdução}

A escrita deste artigo, por ocasião da Oficina de História realizada em Moçambique (2016) inevitavelmente me fez revisitar a pesquisa de mestrado que desenvolvi entre os anos 2004-2006. De início, esta investigação visava analisar a condição social das mulheres de Moçambique após a independência (1975), uma vez que, a literatura
Prof. ${ }^{\text {D }}$.. Jacimara

Souza Santana

Doutora em História Social pela Universidade do Estado de São Paulo (UNICAMP) e professora de História da África da Universidade do Estado da Bahia (UNEB). 
sugeria maior agravo das suas condições de vida e marginalização social em consequência do domínio colonial, entretanto, a pesquisa foi redefinida para a análise das representações da condição social daquelas mulheres nas notícias, reportagens e artigos da revista Tempo, bem como sua sessão intitulada, carta dos leitores' (BOAHEN, 2010: 943; SHELDON, 1952: 46; ZAMPARONI, 1998: 109; SANTANA, 2014: 49-51).

Este artigo trata do processo de produção dessa pesquisa e alguns dos seus resultados, a exemplo de algumas contradições da política de emancipação empregue pelo Estado após a independência e reações desenvolvidas por mulheres a sua proposta.

O interesse por estudar história da África surgiu do meu engajamento no movimento negro brasileiro ${ }^{2}$ a partir de finais dos anos 1980. Algo que chamava a minha atenção neste movimento era a grande importância dada a "África", assumida como a "Terra Mãe" das populações negras e um referencial no processo de reconstrução da identidade racial, muito embora o continente africano fosse pouco conhecido, (HALL, 2003: 25-50; GILROY, 2007: 123-132; CAPONE, 2004; 255-336). Essa e outras constatações foram despertando o meu interesse para o estudo de história da África como uma necessidade de conhecer para desfazer mitos, estereótipos e ensinar.

A necessidade de conhecer e ensinar história e cultura africana era uma antiga reivindicação pan-africana. A $1^{a}$ Conferência dos Povos Africanos do Mundo, realizada em Nova York, no ano de 1920 aprovou uma declaração de direitos que condenavam o colonialismo e o racismo e a inclusão da história da África no ensino. Mais de cinco décadas mais tarde, Abdias do Nascimento, um destacado líder do

1 O fato de identificarmos no Arquivo da Casa de Angola um considerável volume de edições da revista Tempo e de publicações relacionadas às mulheres, assim como, a impossibilidade da realização de pesquisa de campo foram fundamentais para essa mudança.

2 O movimento negro é formado por diferentes tendências e grupos, especificamente fui membro dos Agentes de Pastoral Negros (APNs). movimento negro brasileiro defendeu a difusão do ensino de história da África em todos os níveis de ensino na ocasião do Festival de Artes e Cultura Negra no ano de 1977 em Lagos-Nigéria. Mas somente em 2003, tais movimentos sociais conseguiram converter aquela reivindicação em lei (10.639/03) do Estado nacional.

Apesar de a sociedade brasileira possuir uma identidade multicultural, as heranças africanas permaneciam marginalizadas no currículo. Essa era uma das facetas do racismo no Brasil associada à visão colonial do passado, cuja discussão tendia a ser ensurdecida pelo discurso predominante da democracia racial. Essa contribuição dos movimentos negros impactou no crescimento da produção de pesquisas em história da África no Brasil, criação de núcleos e Institutos de Estudos africanos, assim como na oferta de cursos nas graduações e pós-graduação.

A experiência de pesquisar mulheres de Moçambique entre os anos 2003-2006 impôs vários desafios, dentre os quais, superar o distanciamento da área geográfica da pesquisa. Na primeira fase do trabalho percebi os limites de realizar uma pesquisa da história de um país distante em termos geográficos, apesar das suas interconexões históricas e culturais com o Brasil. O exercício da pesquisa despertou a minha percepção para as diferenças entre aquela África do lado do Oceano Índico e a África presente em nosso cotidiano baiano, nas religiões de matriz africana, nos discursos dos representantes dos movimentos negros ou cantos dos blocos afros, em cujo universo, é transmitida a ligeira impressão de que África é algo de casa, semelhante a um parente distante que está prestes a ser reencontrado, o que reforça mais a ideia de similaridades do que de diferenças. Percebi que estudar história da África não era a mesma coisa que estudar história afro-brasileira.

Por isto, o acesso a filmes e a literatura de Moçambique ofereceram imensa contribuição no sentido de criar maior proximidade do universo cultural das mulheres que apareciam na revista Tempo. Merece destaque os trabalhos 
de Licínio de Azevedo ${ }^{3}$ e de Paulina Chiziane ${ }^{4}$, bem como, as produções de pesquisadoras do Centro de Estudos Africanos da Universidade Eduardo Mondlane, como: Isabel Maria Casimiro, Ana Maria Loforte, Tereza Cruz e Silva, Conceição Osório e Emídio Machiana. Também foi de grande proveito, dialogar com moçambicanos ou brasileiros em trânsito no Brasil ou Moçambique, quer na forma on line ou presencial. No período da realização da pesquisa, com exceção da coleção História Geral da África publicada no Brasil era comum a dificuldade de acesso e circulação de bibliografia específica de história da África no Brasil.

Outra dificuldade enfrentada naquele momento foi a falta de bolsa de pesquisa para a realização de entrevistas e/ou levantamento de fontes no arquivo de Moçambique. Apesar disso, era farto o acesso às edições da revista Tempo no acervo da Casa de Angola, situada na cidade de Salvador-Bahia, sendo também considerável o volume de notícias relacionadas às mulheres em suas edições, nas quais, o valor da participação do publico feminino no movimento de luta por independência e da sua emancipação social ganharam notável destaque. Isto me despertou para a importante centralidade da revista Tempo no desenvolvimento da pesquisa, sendo utilizado um total de 513 edições produzidas entre os anos 1975-1985. Outras fontes também foram incluídas, ainda que em menor volume em relação a Tempo: alguns números da revista "Voz da Revolução", "25 de Setembro", artigos do "Jornal Notícias" e "Cadernos Terceiro Mundo", assim como, o Relatório da $2^{a}$ Conferência da OMM (1984). A pesquisa se baseou exclusivamente em fontes escritas na maior parte, periódicos.

A proposta era priorizar o ponto de vista das mulheres e africano na tentativa de contribuir com uma produção "despoluída de etnocentrismos"e da marcante visão ocidental de nossos estudos, a exemplo na área de gênero. Identificamos a

3 "A guerra da água", "A voz dos antepassados", "Mariana e a Lua", "A Prostituta".

4 "Nikete": uma história de poligamia e "Ventos do Apocalipse". necessidade de superar alguns limites teóricos da literatura consultada para melhor análise das mulheres africanas que apareciam na revista Tempo, como por exemplo: os conceitos de público e privado, maternidade ou mesmo a tendência não interseccional das análises. Alguns desses limites também se aplicavam as análises das mulheres negras brasileiras (LOFORTE, 2000: 17-22; CRENCHAU, 2002: 171-188; CASIMIRO, 2004: 109-121; OYĖWÙMI, 2004: 1-8; AMINA; 2008: 215234; ADESINA, 2012: 195-196).

Essa pesquisa que eu considero introdutória por ter sido feita a distância das mulheres envolvidas no processo e dos arquivos de Moçambique possibilitou alcançar uma premiação do Ministério da Cultura e Biblioteca Nacional no Brasil, tornando possível sua publicação em forma de livro no ano de 2014, o "Mulheres africanas de Moçambique". Também indicou novos temas de investigação que favoreceram a minha ida a Moçambique nos anos de 2009 e 2012 para a realização de levantamentos de fontes em arquivos e de entrevistas nas Províncias de Gaza e Maputo 5 .

Buscou-se, na medida do possível, explorar o ponto de vista feminino (HILL COLLINS, 2000: 228; BAIRROS, 1995: 458-463) através das entrevistas e reportagens com mulheres publicadas naquele periódico. Isto contribuiu para a percepção de iniciativas de apropriacão ou resistência manifestadas por elas nos discursos veiculados na revista Tempo. Essa revista foi indicada como responsável da tarefa de apoiar a política social de emancipação feminina promovida pelo Estado independente

5 Trata-se da pesquisa de doutorado que partiu da observação da predominância das mulheres no exercício de sacerdotisas (Tinyanga ou "curandeiras") nas reportagens publicadas na revista Tempo, nas quais, a divulgação dessa função aparece marcadamente desprestigiada. Situação não muito diferente também foi identificada em fontes do período colonial. Relacionando fontes orais e escritas, a pesquisa procurou mostrar como Tinyanga conseguiram garantir a existência do seu grupo social, manter o controle sobre os seus próprios recursos e a legitimidade de seu conhecimento num contexto político marcado por intensas mudanças decorrentes dos processos de colonização e independência. O período do trabalho abrangeu os anos de 1927-1988. 
(1977). O compromisso de sua redação com os interesses deste Estado torna o discurso da Frelimo hegemônico em suas edições, mas não o único. Se de um lado emerge em suas páginas uma imagem otimizada da mulher revolucionária, nacional, sem raça, etnia e classe do outro, aparecem imagens das mulheres em seu cotidiano. A análise dessas variantes possibilitou identificar ações de mulheres ora manifestando resistências a esse discurso político, ora se apropriando e intervindo na sua reformulação.

Apesar de bastante noticiadas, as mulheres escreviam pouco na revista Tempo e a maioria delas não liam em língua portuguesa. Contudo, 0 uso das reportagens fotográficas foi um aspecto generalizado e uma estratégia utilizada por seus editores para tornar a revista útil à população. Em entrevista a Tempo, Helena Macucule, operária de uma fábrica de caju demonstrou que o fato de muitas mulheres não saberem ler, escrever ou falar o português ${ }^{6}$ não significou exclusão de acesso a informações e a revista:

\footnotetext{
Quando vemos por aí fotografias da luta, das mulheres que trazem filho nas costas, panelas nas cabeças, machados e armas em punho, para nós, que não estudamos dá-nos a conhecer que a mulher tem valor e luta como o homem porque é dessa maneira que ganhamos a nossa terra. Por isso decidi entregar-me e que mais outras se entreguem, para que nos encontremos unidos, homens e mulheres, sermos membros do Partido, determinados na edificacão do nosso País?.
}

Elas podiam não saber ler nem escrever o português, mas algumas delas tomaram-se

6 O censo de 1980 publicado na Tempo mostrou grande desproporção no acesso ao ensino por gênero. Em uma mostra populacional de 9.682 .267 pessoas, em que 4.713.245 eram homens e 4.969.022 mulheres, se identificaram um total de 7.261.417 analfabetos, sendo que 2.980 .783 correspondiam ao total de homens e 4.280.634 ao de mulheres. Conforme estatística, o analfabetismo atingia a maioria da população. No entanto, sua incidência era maior entre as mulheres (Tempo. 1978: 33, n. 423, p. 33, 12 nov. 1978).

7 Tempo n. 625, p.18-31, 3 out. 1982; Tempo, n. especial, p. 28, 25 jun. 1975. convencidas de que aquela revista era um espaço onde podiam e tinham o direito de se expressarem. Com base nesta certeza é que uma mulher idosa vendedora de peixe abordou certa vez alguns funcionários daquela revista, afirmando: "vocês são da revista Tempo não é? Quero falar e peço que publiquem a melhor das minhas expressões na revista".

\section{Notícias de Mulheres no Movimento de Libertação Nacional}

\begin{abstract}
Quando nós mulheres começamos a trabalhar, houve forte oposição à nossa participação porque isso era contrário à nossa tradição. Iniciamos então uma grande campanha, explicando por que razão nós também devíamos combater, que a guerra desencadeada pela FRELIMO era uma luta popular, na qual todo o povo devia participar que nós mulheres éramos mesmo mais oprimidas que os homens, que tínhamos os mesmos direitos e a mesma determinação de combater. Insistimos para que nos fosse dado treino militar e armas. (REVISTA VOZ DA REVOLUÇÃO, 1979: 28)
\end{abstract}

Assim afirmou uma das ex-combatentes participante do primeiro treinamento político- militar para mulheres da Frente de Libertação de Moçambique (FRELIMO) ${ }^{8}$. Esse treinamento ocorreu em Nachingwea-Tanzânia, no ano de 1967. A entrada das mulheres para o exército da FRELIMO com a finalidade de atuar nos confrontos armados em favor da independên-

8 A FRELIMO resultou da "fusão" de outros três grupos nacionalistas organizados em países vizinhos de Moçambique: a UDENAMO (União Democrática Nacional de Moçambique) formada em 1960, em Salisbury, capital da então Rodésia e atual Zimbábwè; a MANU (Mozambique African National Union), fundada em Tanganica e localizada na atual Tanzânia em 1961; a UNAMI (União Africana de Moçambique Independente) fundada em Niassalândia, atual Malauí em 1961. Embora estes grupos tivessem como interesses comuns a conquista da independência havia, entre eles, diferentes correntes políticas que caracterizavam seus anseios. Assim, o acordo de união não significou ausência de contradições. 
cia de Moçambique foi determinante para o desencadeamento de discussões relacionadas às mulheres e o seu lugar na sociedade tanto no interior daquele movimento de libertação nacional quanto da política do Estado após a conquista da independência. Depoimentos de mulheres ex-combatentes registrados em periódicos como "Revista Tempo" e "Voz da Revolução", a exemplo do supracitado em epígrafe, dão uma noção do significado dessa experiência.

Nesse primeiro depoimento, cujo nome da autora a redação não fez questão de registrar, mostra não ter sido consenso entre os membros da FRELIMO ou mesmo dentre a população, o fato de algumas mulheres decidirem tornarem-se guerrilheiras. Conforme depoimento, essa atitude implicou no enfrentamento de reprovações e na insistência por "armas e treinamento", de modo que, elas próprias tiveram de garantir a sua iniciativa. Desde 1965 que um grupo de mulheres Macondes haviam solicitado treino militar a FRELIMO, algumas delas se mobilizaram neste sentido por entender que a luta contra a colonização portuguesa e por independência do seu país fazia parte de sua própria libertação.

A depoente supracitada, por exemplo, é uma mulher Maconde e ao levar em consideração a experiência de opressão sofrida por mulheres durante o período colonial, afirmou: "os colonialistas portugueses eram muito maus, as mulheres não eram respeitadas e mesmo as casadas eram violadas na frente de seus maridos. Se estes reagissem ou se aquelas se recusassem ambos eram barbaramente espancados, os colonialistas argumentavam que era uma honra para uma mulher negra ser desejada por um homem branco". Ademais comentou sobre a exploração a que eram submetidas devido ao trabalho forçado nas plantações de algodão, o que as impedia de regulamente realizar trabalho em sua suas próprias machambas.

Filomena Likune uma das primeiras 25 mulheres Macondes a receber treinamento em Nachigwea, também manifestou alguns comentários a respeito da sua experiência de combatente em uma entrevista a Revista Tempo. Segundo Likune, considerava-se que as mulheres deveriam atuar nas atividades de apoio ao movimento de libertação, a exemplo, da produção de alimentos nas machambas. $O$ avanço da guerrilha era reconhecido como uma tarefa dos homens e o Comitê Central do movimento decidiu, em 1966, atender ao pedido de algumas mulheres tornarem-se guerrilheiras por experiência. Entretanto afirmou Likune, Nos treinos iniciados em 1967, "os resultados foram excelentes! Nenhuma de entre nós caiu durante os treinos, corríamos grandes distâncias sem problemas, conseguimos convencer sobre a nossa capacidade" (VOZ DA REVOLUÇÃO, 1970: 21).

Mônica Chitupila, também integrante daquela primeira turma de mulheres guerrilheiras, em entrevista a Revista Tempo, afirmou:

Fazíamos o trabalho de mobilização do
povo, de produção agrícola para alimen-
tar os combatentes. O nosso trabalho era
importante porque havia pessoas que es-
tavam convencidas de que a guerra seria
de curta duração e então desesperavam.
Tínhamos de encorajá-las. Íamos fazen-
do estas tarefas, mas só depois do treino
político em Nachingwea, a nossa ação se
mostrou mais vigorosa. Em 1967 fiz parte
do primeiro grupo que partiu do Niassa
para treinar em Nachingwea juntamen-
te com as mulheres de Cabo Delgado [...]
cerca de 40 mulheres começaram os tra-
balhos na base. (REVISTA TEMPO, 1982: 23)

Desde a fundação do movimento nacionalista, em 1962, que as mulheres já vinham demonstrando iniciativas de colaboração. O trabalho de mobilização popular ampliava a adesão e recrutavam pessoas para a luta por independência e contra o colonialismo, algumas delas já trabalhavam na defesa das populações ainda que não tivessem formação técnico-militar, como foi o caso do grupo de Macondes já mencionadas. Mulheres também trabalhavam na assistência de saúde e no transporte de armamentos. Na região sul, dentre as mulheres das zonas urbanas destaca-se as que atuavam no Núcleo dos Estudantes Secundários Africanos 
de Moçambique (NESAM), das cidades de Maputo e Xai Xai, havendo entre essas algumas que também decidiram fazer parte da FRELIMO de um modo mais radical, a exemplo de Josina Muhemba Machel (1965) que chegou a atuar na chefia de seu Departamento de Relações Exteriores e Assuntos Sociais, além de participar de discussões importantes relacionadas às diretrizes do movimento de libertação e a participação das mulheres em seu $\mathrm{II}^{\circ}$ Congresso, em 1968 (ISAACMAN, 1984: 23; TEMPO, 1975: 19, n. 756; TEMPO, 1982: 13. 31, n. 629).

A entrada das mulheres para o movimento de libertação nacional enquanto guerrilheiras e o seu reconhecimento por meio da fundação oficial de um Destacamento Feminino da FRELIMO, em 1968, suscitou ganhos políticos para elas, mas também reações agressivas por parte de alguns membros daquele movimento. Alguns tentaram investir contra as mulheres por acreditarem que elas deveriam continuar se ocupando com atividades da vida familiar, havendo até quem apelasse para a desmoralização das envolvidas na luta armada Outro impacto dessa participação se refletiu no lugar que as discussões sobre o papel social das mulheres e a sua emancipação passaram a ocupar nas discussões do movimento FRELIMO (VOZ DA REVOLUÇÃO, 1978: 3; OMM, 2008: 9).

\section{Política de Emancipação Feminina e suas Contradições}

Antes mesmo da conquista da independência, em 1973, a direção da FRELIMO convocou

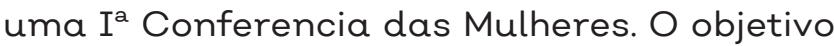
dessa convocatória foi discutir com mulheres das diversas regiões de Moçambique a condição social da população feminina e sugerir estratégias para a sua emancipação. O discurso de Samora Machel na abertura dessa conferência revela a persistência de contradições entre seus membros a esse respeito. Segundo Machel, para uns, a prioridade naquele momento era a destruição das estruturas do colonialismo, sendo a emancipação das mulheres uma tarefa secundária e algo a ser tratado após a independência quando o país pudesse contar com uma base econômica, social e educacional sólida. Na visão de outros, investir na emancipação das mulheres exigia um sistema educacional estruturado, pois isso implicava não somente em alfabetizá-las, mas conscientizá-las das novas concepções relativas à identidade da mulher revolucionária, uma vez que a maioria ainda se encontrava muito "apegada à tradição". Também havia quem considerasse que as mulheres não estavam sensibilizadas para isso, tratando-se de algo artificial e uma invenção que alguns líderes da FRELIMO impunham às mulheres (MACHEL, 1979: 16-18).

A visão de Samora Machel, na condição de presidente da FRELIMO e de Moçambique após a independência destoava dos demais, em um dos fragmentos de seu discurso ele afirmou:

A libertação da mulher é uma necessidade fundamental da Revolução uma garantia de sua continuidade, uma condição de seu triunfo. A Revolução tem por objetivo essencial a destruição do sistema de exploração, a construção de uma nova sociedade libertadora das potencialidades do ser humano e que o reconcilia com o trabalho, com a natureza. É dentro deste contexto que surge a questão da emancipação da mulher. Não se pode liquidar só uma parte da opressão [...] Como fazer então a Revolução sem mobilizar a mulher? Se mais da metade do povo explorado e oprimido é constituido por mulheres, como deixá-las à margem da luta? A Revolução para ser feita necessita mobilizar todos os explorados e oprimidos, por consequência, as mulheres também. (MACHEL, 1979: 18)

Machel concebia a emancipação feminina e o processo revolucionário ${ }^{9}$ como indissociáveis. Ele entendia a opressão feminina enquanto uma consequência direta do sistema econômico ao

9 Este termo possui várias interpretações, mas, grosso modo, significa um movimento social que procura reconstruir uma nova ordem na sociedade, mudar seu corpo dirigente e sistema político. A proposta da FRELIMO incluía a conquista da independência e a construção de um governo africano, descolonizado, popular, democrático e socialista. 
invés de um problema a ser resolvido entre o homem e a mulher, muito embora considerasse que a eles coubessem mudança de mentalidades e de comportamento, a emancipação feminina era, sobretudo vista, como um resultado do sucesso do socialismo e da iniciativa das mulheres. Essas deveriam se conscientizar de suas capacidades e superar o espírito de inferioridade, submissão e passividade que thes tinha sido incutido pelas tradições culturais e pelo colonialismo. Para garantir o engajamento feminino após a independência, Machel não somente sugeriu, mas fundou neste evento uma Organização das Mulheres Moçambicanas, a OMM, entretanto sem integrar na sua direção mulheres do D. F. que vinham atuando na luta de libertação, ainda que, o tenha tornado um núcleo daquela organização (MACHEL, 1979:34).

Entrevistas de mulheres líderes da OMM e do D.F. publicadas na Revista Tempo em 1976 revelam que mulheres ex-combatentes de significativa contribuição no passado mostraram-se desmotivadas na OMM. A tendência destas lideranças do tempo da luta por independência foi sair dessa organização, o que ocasionou a sua inoperância. A fundação da OMM funcionou como um freio às ações que as líderes do D. F. já vinham desenvolvendo. A OMM não atuava enquanto uma organização autônoma, mas em sintonia com os propósitos do partido e governo. Sua função principal era trabalhar pela emancipação feminina e isto consistia em envolver as mulheres nas tarefas da Revolução e fazer com que elas conhecessem a linha política da Frelimo (II ${ }^{2}$ CONFERÊNCIA DA OMM: engajar a mulher na tarefa principal. TEMPO, n. 323, p. 26-27, 12 dez. 1976; CASIMIRO, 2004: 175-176).

A política de emancipação promovida pelo Estado de Moçambique após a independência propiciou às mulheres ter acesso a novos papéis na sociedade. Em decorrência dessa política, mulheres foram incentivadas a atuarem como militantes filiadas ao Partido e a OMM, se pronunciarem em público, inserir-se no mercado de trabalho assalariado, adquirir formação técnica, alfabetizarem-se, fazer parte do exército e da polícia. A OMM foi o órgão responsável por mobilizá-las. A revista Tempo veiculou imagens desse novo modelo de ativismo das mulheres acompanhado do ideal de igualdade de diretos entre homens e mulheres.

Edições da Revista Tempo publicadas após a independência evidenciaram notícias e fotografias da participação de mulheres em treinos militares. Com exceção das antigas ex-combatentes que passaram a integrar o exército das Forças Populares de Libertação de Moçambique (FPLM), mulheres continuaram a ser preparadas para atuar nos Grupos de Vigilância Popular, de modo a detectarem áreas minadas, utilizar armamentos e tomar iniciativas em caso de ataques às aldeias (TEMPO, 1981: 12-15; TEMPO, 1982: 16-19). Essa atuação foi propagada como um socorro em razão das agressões armadas que Moçambique passou a sofrer em função da independência e do rompimento de relações políticas com a África do Sul em função do seu regime colonial e de apartheid. Após a independência em 1975, o país enfrentou mais dez anos de confrontos armados liderados com a emergência do Movimento de Resistência Nacional, a RENAMO'10.

A secretária da OMM de Gaza, Maria José Mucavele, em entrevista a revista Tempo afirmou que aquele trabalho feminino ajudava a impedir invasões nas aldeias e prender grupos armados (Tempo, 1982: 17-18). Lúcia Antônio, secretária provincial de Manica, também afirmou em entrevista naquela revista que apesar do alvo da RENAMO ter sido as grandes áreas de produção econômica, suas maiores vítimas eram as mulheres e as crianças (TEMPO, 1984: 22-23). A OMM havia treinado 10.000 milicianas em todo o território e algumas dentre essas mesmo depois de terem sido vítimas dos ataques, continuaram a exercer suas atividades como secretárias da OMM e em socorro do sofrimento de outras mulheres (SHELDON, 1984: 45).

Além do papel de milícias, as mulheres também foram noticiadas na Revista Tempo como

10 Para maiores informações ver: GEFFRAY, C. A Causa das armas: antropologia da guerra contemporânea em Moçambique. Porto: Afrontamento, 1991. 
responsáveis por construções de moradias. Tratou-se de uma campanha de construção de casas familiares incentivada pelo Gabinete de Urbanização e Habitação do Estado (TEMPO, 1976: 21). Esse papel era exclusivamente masculino tanto nos agrupamentos familiares de influência matrilinear ou patrilinear". Na revista Tempo, a imagem da mulher atuando na construção de casas em diferentes Províncias do país foi bastante massificada, inclusive na construção de centros para o desenvolvimento de atividades da OMM (TEMPO, 1982: 25).

Outro papel desempenhado por mulheres e noticiado naquele periódico foi o de juízas nos Tribunais Populares. No modelo de organização social ancestral, este cargo somente podia ser exercido por homens mais velhos e/ou chefes africanos, sendo esse exercício feminino visto como uma posição de prestígio para elas. Maria Luisa Fernando Moiana, juíza eleita pelo operariado da fábrica de confecções Ninita, em Maputo, em entrevista a revista Tempo afirmou que através dessa atividade ela podia tomar decisões para resolver os problemas da população e orientar os juízes de formação acadêmica que, por vezes, se mostravam inexperientes na resolução de certos casos que exigiam o conhecimento da cultura local (ISAACMAM, 1984: 42).

Mulheres também foram noticiadas como membros do partido e deputadas nas páginas da revista Tempo. Apesar disso, o acesso delas às Assembleias Populares e reuniões do partido era marginal. Nos resultados da campanha de estruturação do partido Frelimo em 1978 notou-se presença predominante dos homens nos cargos de direção, com exceção da Província de Cabo Delgado, em cujo distrito de Macomia (Cabo Delgado) 50\% dos membros eleitos foram mulheres. Situação similar foi identificada na fábrica de Caju, em Chamanculo (Maputo),

11 Nos sistemas de parentesco, a pertença das pessoas ao grupo de descendência se estabelece por filiação transmitida pela família da mãe, matrilinear ou do pai, patrilinear. Trata-se de um sistema de organização social muito diverso, apesar de possuírem alguns aspectos comuns. onde a maioria do operariado era composta por mulheres (ISAACMAM, 1984: 32-39)12.

Ademais, nas atividades dos Partidos as mulheres eram as únicas responsáveis pela limpeza, cozinha, atividades culturais, cuidados de saúde e educação. De um modo geral, a presença feminina no governo se deu muito mais em nível periférico, com maior impacto nos distritos e bairros, apesar de a revista Tempo noticiar que mulheres participavam dos Congressos da Frelimo na condição de delegadas. Nas comemorações ao dia 7 de abril de 1983, a revista entrevistou cinco mulheres em um grupo de seis delegados para o IV ${ }^{\circ}$ Congresso (1983): Lúcia Nhkota, membro do destacamento feminino e da Frelimo desde 1965; Amélia Chamusse e Delfina Julieta Bila, donas-de-casa e lideranças de organização das mulheres nos bairros; Guilhermina Filipe, operária da indústria de caju de Machava; e Lina Mkhala, camponesa de Cabo Delgado e membro de uma cooperativa (TEMPO, 1983: 19).

Enfim, a política do Estado após a independência proporcionou às mulheres ocuparem novos papéis sociais e ganhar maior visibilidade pública, mas ao mesmo tempo mostrou-se profundamente contraditória com a proposta de emancipação das mulheres. O incentivo a ocupar novos papéis sociais não mostrou-se imcompativel com a exigência de que as mulheres continuassem a exercer velhas funções vistas como próprias do feminino. Salomé Moiane, em entrevista a Tempo, afirmou que as mulheres

12 Essa configuração das moçambicanas na política modificou-se na década dos anos 90. Segundo Isabel Casimiro, Moçambique foi o primeiro país na África em termos de mulheres no Parlamento, totalizando na altura dos anos 1990, $28 \%$ e um dos poucos a inscrever a dimensão de gênero nos programas do governo, saindo de uma eleição multipartidária, enquanto que em nível mundial a representação feminina no Parlamento decrescia de $14.8 \%$ (1988) para $11,7 \%$ (1997). Para maiores informações sobre a participação das mulheres na política consultar: OSÓRIO, C. Poder político e protagonismo feminino em Moçambique. SANTOS, B. de S. Democratizar a Democracia. Reinventar a Emancipação Social. $2^{a}$ edição. Rio de Janeiro: Civilização Brasileira, 2003, v 1, pp. 421-49 e CASIMIRO, I. Paz na Terra Guerra em Casa. Feminismo e Organização de Mulheres em Moçambique. Maputo: Promédia, 2004 pp. 125-144. 
estavam respondendo aos incentivos do partido e da OMM ao aderirem à campanha de alfabetização e/ou se envolverem em diferentes atividades nas áreas da saúde, defesa, produção e justiça, entretanto acrescentou que a OMM também estava investindo em cursos de educacão nutricional, sanitária de higiene e limpeza, além de oferecer cursos de corte e costura para que as mulheres pudessem aprender a fazer uma bainha e roupas para seus filhos. Para Moiane, a participação das mulheres nestes cursos era necessária para que elas pudessem ter um bom desempenho nas suas funções de mães, esposas e educadoras das suas crianças (TEMPO, 1983: 30-34).

Essa contradição ainda tornou-se expressiva quando o Estado lançou uma campanha de limpeza e conservação das casas reconhecendo essas atividades como exclusivas das mulheres (TEMPO, 1983: 15). Por costume, os cuidado com a moradia e a educação dos filhos era um dever das mulheres e essa política de Estado ou a OMM não contrariou esse entendimento, sendo aquelas as principais responsabilizadas pelos danos dos imóveis como também por sua conservação. A divisão do trabalho doméstico foi um tema ausente das discussões relacionadas a emancipação feminina proposta pela Frelimo e OMM. Essa campanha teve grande impacto na preparação do IV ${ }^{\circ}$ Congresso da Frelimo.

A nacionalização das casas após a independência incentivou a migração de famílias das zonas rurais para os espaços urbanos, passando algumas a ocuparem os prédios das "cidades de cimento". A revista Tempo, eventualmente alertou para o uso do espaço residencial nas cidades, atribuindo às mulheres a responsabilidade quase exclusiva do seu "mau uso", condenando a exemplo, a plantação de hortas dentro dos banheiros, pilar milho dentro dos apartamentos ou o ato de trançar cabelos nas ruas (TEMPO, 1983: 26). Em 1977 Machel, em um dos seus discursos dirigidos à população de Beira alertou a OMM para o fato de que as escolas, sobretudo as das capitais, deveriam ensinar as mulheres a manterem uma casa. Isto foi propagandeado como um ato de patriotismo das mulheres (TEMPO, 1982: 15). O entendimento que Machel tinha da emancipação feminina é flagrante em outro de seus discursos:

Há quem conceba emancipação como uma igualdade mecânica entre homem e mulher. A emancipação seria, então, a mulher e o homem fazerem exatamente as mesmas coisas, dividirem mecanicamente as tarefas no lar [...] A emancipação concebida mecanicamente leva como vemos, por exemplo, nos países capitalistas, a reclamações e atitudes que deturpam inteiramente o sentido da emancipação da mulher. A mulher emancipada é a que bebe, a que fuma, é a que usa calças e mini-saia, a que se dedica à promiscuidade sexual, a que recusa ter filhos. [...] Outros identificam a emancipação com a acumulação de diplomas, aparecendo em particular o diploma universitário como um certificado de emancipação. Há ainda quem considere que a emancipação consiste em aceder- se a um nível econômico, social e cultural. Todas estas concepções são erradas e superficiais. Nenhuma delas atinge o coração da contradição nem propõe uma linha que verdadeiramente emancipe a mulher (VOZ DA REVOLUÇÃO, 1978: 45, n. 68).

Dessa forma, conciliar participação política e trabalho doméstico era uma tarefa individual das mulheres. Em homenagem ao dia das mulheres moçambicanas de 1982, a Tempo em artigo intitulado "mulheres a libertação foi conquistada" - afirmou que a restrição das mulheres à função de reprodutoras no lar e no campo era uma marca do passado, embora o trabalho domiciliar visto como uma "obrigação" feminina ainda fosse um aspecto pouco questionado e houvesse discriminação salarial por gênero, apesar de a lei estabelecer o contrário (TEMPO, 1982: 14-17). Esta situação era responsável por gerar dupla jornada de trabalho para as mulheres, quer aquelas residentes em zonas rurais ou urbanas, uma vez que, no caso da maioria delas, o sustento familiar era assumido por elas próprias através do trabalho no comercio e na agricultura. 
Uma das grandes exigências do serviço doméstico e que ocupava muito o tempo de muitas mulheres tanto nas zonas urbanas quanto rurais era a aquisição de água. Para atender a essa necessidade elas enfrentavam filas e percorriam grandes distâncias, nem sempre com êxito. Nina Swain, ao entrevistar 200 mulheres de 40 aldeias dos distritos de Bárue, Guro e Tambara da Província de Manica constatou que enquanto mulheres exerciam essa tarefa como uma extensão do trabalho doméstico não pago, alguns homens o executavam mediante pagamento. A procura por água geralmente exigia o emprego de muitas horas e era feita em mutirão e criava um espaço de sociabilidade entre as mulheres (TEMPO, 1982: 25-28).

Para Salomé Moiane, um grande mérito das mulheres consistia em saber realizar o duplo esforço de participar na produção e garantir um bom ambiente familiar. Desse modo, elas assumiam mais funções políticas do que os homens. Geralmente aquelas que exerciam o cargo de secretárias da OMM também eram membros do partido, podendo ser escolhidas para deputadas, juízas e representantes da organização em encontros internacionais (TEMPO, 1977: 26), - que fazia com que ocorresse uma constante rotatividade das lideranças na OMM. Por motivo de cansaço, tendiam a abandonar a organização ao longo do tempo (ISAACMAM, 1984: 42).

Algumas mulheres ativistas, por vezes, também eram impedidas de participarem das reuniões e atividades por seus maridos. Este foi um dos aspectos abordados por Machel em seu discurso dirigido à população da Província de Niassa (1979), quando chamou a atenção dos homens contra essa atitude alertando-os para o fato de que a participação das mulheres nas várias tarefas da revolução e no trabalho assalariado era uma necessidade para a sua emancipação (TEMPO, 1979: 42). Embora Machel contestasse o autoritarismo dos maridos e defendesse o direito de participação política para as mulheres ele era a favor de que elas não comprometessem o seu estatuto de esposas e mães, nem mesmo a autoridade marital ou o casamento.
Apenas em sua IV ${ }^{2}$ Conferência Extraordinária de 1984, a OMM demonstrou mudanças nesse sentido. Homens foram incentivados a realizarem serviços domésticos e se criou maiores possibilidades para que as mulheres ocupassem profissões até então exclusivas do masculino. A partir dessa Conferência surgiu na revista Tempo uma sessão intitulada "Mulher", na qual, a redação da revista passou a publicar testemunhos individuais de carreiras profissionais femininas, embora a oportunidade de emprego assalariado ainda não fosse uma ampla realidade para elas devido a desigualdade de formação educacional em relação aos homens, sendo o seu predomínio no campo da agricultura e no mercado informal (MORA, 1999: 54-55)

O fato de a emancipação feminina ter se tornado uma política social do Estado após a independência não implicou em mudanças significativas das condições de vida para as mulheres. Isto se explica por diferentes fatores de ordem econômica e política dos primeiros anos da independência de Moçambique, mas também tem relação com o conceito de emancipação feminina adotado na política e programas do Estado e OMM. Sua concepção tinha por base influencia teórica do marxismo que preconizava o fim das opressões sociais a desestruturação do sistema capitalista, sendo a subordinação feminina vista como um resultado da exploração própria daquele sistema, um problema a ser resolvido em consequência do estabelecimento do Estado socialista e moderno. De um modo em geral, este pensamento fez parte do discurso socialista de diferentes países assim como o pouco avanço da situação das mulheres apesar do envolvimento delas em lutas nacionalistas. Análises de feministas socialistas apontaram para limites da teoria marxista no trato de questões relacionadas às mulheres, gênero ou mesmo raciais.

No caso de Moçambique também é preciso considerar as influencias da formação religiosa de seus líderes e o modelo de desenvolvimento adotado pela Frelimo (ARNFRED, 2015: 181-224; CASIMIRO, 2005: 55-84; Borges, 2001: 226). Ademais, o fato de as mulheres não ter sido vistas 
como agentes de sua emancipação, mas beneficiárias de políticas que se pensava gerar emancipação para elas deu origem a muitas das contradições, algumas delas já citadas neste texto (BAZIMA, 1979: 19-37; SANTOS, 2003: 43-51). É partindo dessa visão que a política social, em tese destinada a libertar as mulheres da opressão se transforma em instrumento de vigilância e controle do comportamento social das mulheres.

É o que se nota, por exemplo, no incentivo a censura de certos comportamentos de mulheres das zonas urbanas, como a prática de beber ou o fato de serem mães solteiras. Similar tendência é identificada nas campanhas de combate a algumas práticas culturais como: ritos de iniciação, poliginia e atividades exercidas por líderes das religiões ancestrais (Tinyanga). Tais práticas foram consideradas como uma pecha ao desenvolvimento e a emancipação feminina, sendo as mulheres vistas como suas maiores difusoras, além de vítimas e a OMM como a maior responsável por seu combate.

\section{Notícias de Reinvenções do Modelo de \\ Emancipação Feminina}

O modelo de emancipação feminina promovido pelo Estado de Moçambique após a independência mostrou-se hegemônico nas edições da revista Tempo - de homens para as mulheres e de caráter socialista -, entretanto, a mesma revista que veiculou imagens homogêneas das mulheres moçambicanas, sem etnia, raça ou classe, também registrou algumas de suas intervenções àquele modelo político, quer na forma de apropriação, negação ou indiferença a tais discursos de emancipação, em benefício de seus interesses individuais ou coletivos.

\section{Mulheres da Indústria Caju}

O desabafo de funcionárias de uma indústria produtora de castanhas em prol de condições mais dignas de trabalho também teve lugar nas páginas da revista Tempo. Ao rememorar as duras condições de trabalho no tempo colonial, Ester Manjate, uma das operárias do descasque que passou a ser representante da OMM nesta empresa, confessou que no passado era comum às mulheres passarem fome durante as nove horas de trabalho por que o consumo da castanha era proibido e em caso de desobediência muitas delas podiam ser espancadas e ou presas. As mulheres recebiam um baixo salário e a realização de todo serviço era feita manualmente. A constante exposição à poeira lhes causava doenças pulmonares e, além disso, ainda eram expostas a humilhações e chantagens sexuais por parte dos patrões que não hesitavam em espancá-las, mesmo tendo filhos às costas, estando grávidas ou sendo idosas.

Após a independência, alguns desses problemas ainda persistiram. Ainda que a maioria empregada fosse de mulheres, totalizando, em 1979, 1.709 trabalhadoras dos 2.160 funcionários. As trabalhadoras conviviam com a ameaça de desemprego em face de quaisquer manifestacões de contrariedade. Reclamaram ainda as trabalhadoras de haver boicote na formação política e diferença salarial por sexo.

Mas para Ester Manjate, o discurso da emancipação feminina deveria soprar ventos a favor de mudanças. Em sua entrevista, disse que foi por iniciativa das trabalhadoras que se conseguiu mudar uma prática até então proibida: o preenchimento das latas de castanhas. Para ela, isto era uma forma de exploração porque o salário era pago mediante o número de latas que elas conseguiam encher. Essa experiência teve início quando uma das trabalhadoras tomou uma lata das mãos de Ester Manjate, vestiu calças e passou a encher as latas de castanhas. Em princípio a atitude serviu de motivo para brincadeiras, mas, aos poucos, passou a ser uma prática assumida pelas outras.

Manjate, convicta da lucidez de sua iniciativa afirmou que seguia as orientações dos documentos da Frelimo que dizem que a mulher deve realizar trabalho feito pelo homem. Embora tal pronunciamento e atitude desse a entender que Manjate tinha conhecimento da política da FRELIMO, esta não sabia ler. 
Hermínia Manuense, em sua análise sobre as operárias da Caju, demonstrou outros impactos que o trabalho na cidade trouxe à vida cotidiana dessas mulheres. Além de conseguirem devolver - "lobolo" pago por seus maridos por ocasião do casamento, puderam enviar algum sustento às suas famílias nas zonas rurais e investir na formação de seus filhos, assim como tiveram a possibilidade de morar nas cidades como proprietárias de suas casas, com autonomia financeira e independência do poder marital - aspectos que, por sua vez, introduziram mudanças nas relações conjugais.

\section{Mulheres Macondes no Enfrentamento da Violência Doméstica}

Em um artigo sobre a situação da população feminina Maconde, habitantes entrevistados de Cabo Delgado afirmaram à Tempo que as mulheres daquela região estavam apresentando pedidos de divórcio ao Tribunal Popular de Macomia para se livrarem da prepotência ou adultério por parte dos maridos.

Embora a prática de violência contra as mulheres não fosse uma característica do sistema de parentesco matrilinear em localidades de influência islâmica, a situação das mulheres casadas se mostrava agravante.

As questões mais freqüentes em Macomia diziam respeito a violência doméstica. A Tempo noticiou a iniciativa do pedido de divórcio como um avanço e conquista feminina, apesar de o governo interpretar a iniciativa de divórcio como uma ameaça à família e um entendimento errôneo do conceito de emancipação feminina. Segundo artigo, o divórcio estava sendo utilizado pelas mulheres como "uma forma de testar junto ao homem a sua liberdade de fazer o que entende" quando, de fato, se tratava de uma questão de luta de classes. Samora Machel, em seu pronunciamento na IV ${ }^{2}$ Conferência da OMM, em 1984, manifestou seu descontentamento por "este tipo de solução" arranjada entre as mulheres, pois o número de divórcios estava crescente.
"O inimigo principal não é o homem, mas o sistema". Essas foram algumas das palavras que a Tempo registrou de uma das lideranças da OMM na região de Cabo Delgado. Algumas mulheres tinham aprendido a orientação da Frelimo de que a emancipação feminina se resolveria pela desestruturação do conflito de classe, contudo, apresentar solicitações de divórcio nos Tribunais passou a ser uma estratégia amplamente utilizada por elas para se livrarem dos maus tratos e da violência de seus inimigos mais próximos, seus próprios maridos.

\section{Mulheres em Rede: Uma União de Cooperativas}

Através do programa Zonas Verdes, o governo incentivou a formação de cooperativas nos centros urbanos. Sua produção agrícola e pecuária contribuiu significativamente com a falta de comida nos centros urbanos e forneceu produtos para a venda no mercado interno. Tal programa atraiu um número expressivo de mulheres, que, mobilizadas pela OMM e GDs, ampliaram em curto prazo o número dessas cooperativas. Isto deu origem, em 1980, à formação da União Geral das Cooperativas (UGC), a qual, em 1981, tinha alcançado o total de 24 cooperativas com 1.177 membros, se elevando para 10.500 membros e 194 cooperativas, no ano de 1986. As mulheres ocuparam $95 \%$ do total de seus membros.

A UGC trouxe melhoras à condição social das cooperativistas e tornou-se uma fonte principal para o sustento de suas famílias. A participação nas cooperativas impactou nas relações de poder nas famílias, uma vez que em um contexto urbano as mulheres passaram a contribuir na sustentação do grupo domiciliar como os homens e, na maioria dos casos, seu trabalho era a única fonte de renda da família. Manter o sustento da família já era uma obrigação das mulheres, mas o fato é que agora trabalhavam fora do território pertencente ao agregado familiar como produtoras e não como esposas, podendo dirigir, decidir e participar dos rendimentos de sua produção. 
Concordamos com Isabel Casimiro, Ana Maria Loforte e Teresa Cruz e Silva quanto a ideia de que a UGC foi um meio de empoderamento para as mulheres em decorrência da possibilidade de terem acesso à terra, a créditos, à educação formal, a tecnologias modernas de produção e ao controle democrático das atividades da organização. Além das mudanças nas unidades domésticas, a participação na UCG propiciou mudanças nas relações de poder da comunidade onde elas moravam.

\section{Referências}

ARNFRED, S. Sexuality and Gender Politics in Mozambique. Rethinking Gender in África. Suffolk-Reino Unido: Boydell \& Brewer Ltd, 2011, pp. 39-62, 201-217.

Notas sobre gênero e modernização em Moçambique. Cadernos Pagu, $n^{\circ}$ 45, Jul/Dez, 2015, pp. 181-224.

BAZIMA, A. Mulher e desenvolvimento. A mulher na realização do direito ao desenvolvimento In: AFONSO, A. E. de S. (org). Eu mulher em Moçambique. República de Moçambique. UNESCO e AEMO, 1994, p. 19-37.

BOAHEN, A.A (coord). História Geral da África. A África sob domínio Colonial (1880-1935). 2ed. São Paulo: Editora Ática, 1991.

CASIMIRO, I. Paz na Terra, Guerra em Casa: feminismo e organização de mulheres em Moçambique. Maputo: PROMÉDIA, 2004. "historiografia e representação da mulher em África". p 109-121.

Samora Machel e as Relações de

Gênero. Estudos Moçambicanos 21, (2005), pp. 55-84.
CAPONE, S. A busca da África no Candomblé. Tradição e poder no Brasil. Rio de Janeiro: Livraria Pallas, 2004.

COLLINS, P.H. Intersecting Opressions. Disponível: <https://www.sagepub.com/sites/ default/files/upm-binaries/13299_Chapter_16_ Web_Byte_Patricia_Hill_Collins.pdf $>$. Acesso em: 10/07/2020.

CRENSCHAU, K. Documento para o encontro de especialistas em aspectos da discriminação racial relativos ao gênero. Revista Estudos Feministas. Vol 10. N1/2002, p 171-188

GILROY, P. Entre Campos. Nações, Culturas e o Fascínio da Raça. Tradução de Célia Maria Marinho de Azevedo.et.al. São Paulo: Annablume, 2007.

HALL, S. "Pensando a Diáspora". Da Diáspora. Identidades e Mediações Culturais. Belo Horizonte: UFMJ, 2003.

ISAACMAM, B.; STEFHAN, J. A mulher moçambicana no processo de libertação. Maputo: Instituto Nacional do Livro e do Disco, 1984.

SANTOS, $\mathrm{H}$. dos. O desenvolvimento e a mulher: um outro mundo é possível. Lisboa: SEIES, 2003.

SHELDON, K. Pouders of Grain. A History of women, work, and politic in Mozambique. Portsmouth:Heinemann, 2002.

Women and revolution in Mozambique. In: TÉEREAULT, M. A. Women and Revolution in Africa, Ásia and the New World. Columbia: University of South Carolina Press, 1994, pp. 33-61.

ZAMPARONI, V. D. "Gênero e trabalho doméstico numa sociedade colonial". Lourenço Marques, Moçambique, c. 1900-1940. Revista Afro Asia, 23, 1999, pp. 145-172. 
